\title{
Serinol: small molecule - big impact
}

\author{
Björn Andreeßen ${ }^{*}$ and Alexander Steinbüchel
}

\begin{abstract}
The amino alcohol serinol (2-amino-1,3-propanediol) has become a common intermediate for several chemical processes. Since the 1940s serinol was used as precursor for synthesis of synthetic antibiotics (chloramphenicol). In the last years, new scopes of applications were discovered. Serinol is used for X-ray contrast agents, pharmaceuticals or for chemical sphingosine/ceramide synthesis. It can either be obtained by chemical processes based on 2-nitro-1,3-propanediol, dihydroxyacetone and ammonia, dihydroxyacetone oxime or 5-amino-1,3dioxane, or biotechnological application of amino alcohol dehydrogenases (AMDH) or transaminases. This review provides a survey of synthesis, properties and applications for serinol.
\end{abstract}

Keywords: 2-Amino-1, 3-propanediol, Amino alcohol, Serinol

\section{Introduction}

2-Amino-1,3-propanediol (1,3-dihydroxy-isopropylamine, aminoglycerin or amino-trimethylenglykol) has a molecular formula of $\mathrm{C}_{3} \mathrm{H}_{9} \mathrm{NO}_{2}$ (Figure 1), belongs to the group of amino alcohols and is prochiral. As it is a structural analogue to the amino acid serine, the common designation is serinol. It is very stable, corrosive, hygroscopic, and dissolves very well in water. It has a molecular weight of $91.11 \mathrm{~g} / \mathrm{mol}$, melts at 52 to $56^{\circ} \mathrm{C}$, and has a boiling point of 115 to $116^{\circ} \mathrm{C}$. The term "serinol" also describes the group of C-substituted commercial analogs. As it is the case for most amino acids, serinol and its derivatives are often used intermediates in several chemical applications. In many organisms mostly eukaryotic serinol derivatives function as central second messengers. In a few prokaryotes serinol occurs as an intermediate of toxin synthesis. In this paper, we review the biological and chemical synthesis and applications for serinol and of some of its derivatives.

\section{Natural occurrence of serinol}

Serinol occurs in sugarcane (Saccharum officinarum), where it can mediate the biosynthesis of the toxin helminthosporoside (2-hydroxycyclopropyl- $\alpha$-D-galactopyranoside) by the pathogenic fungus Helminthosporium sacchari (Babczinski et al., 1978). Enzyme activity for serinol synthesis was measured with crude leaf protein

\footnotetext{
* Correspondence: bandr_01@uni-muenster.de

Institut für Molekulare Mikrobiologie und Biotechnologie, Westfälische Wilhelms-Universität Münster, Corrensstraße 3, D-48149 Münster, Germany
}

extracts, pyridoxal-5-phosphate, dihydroxyacetone phosphate (D, HAP), and alanine. A $K_{\mathrm{m}}$ value of 0.1 to $1 \mathrm{mM}$ for serinol was determined for this enzyme. They also discovered that glutamine, glutamic, as well as aspartic acid served as amino donors for the transaminase with similar efficiencies. However, the responsible gene and protein for the transamination reaction, respectively, have not been unraveled so far.

Serinol also constitutes an intermediate in rhizobitoxine, i. e. 2-amino-4-(2-amino-3-hydropropoxy)-transbut-3-enoic acid, biosynthesis by the plant pathogen Burkholderia andropogonis (Mitchell et al 1986) and the legume symbionts Bradyrhizobium japonicum and its close relative Bradyrhizobium elkanii (Owen et al. 1972). Rhizobitoxine is a well known inhibitor of ethylene biosynthesis. Due to this inhibition, an increased rhizobitoxine production enhances nodulation and competitiveness on Macroptilium atropurpureum, the purple bush-bean, or siratro (Yuhashi et al., 2000). Rhizobitoxine synthesis was most thoroughly investigated in B. elkanii. Tn5 insertion in the $r t x A$ gene of $B$. elkanii caused a rhizobitoxine null mutant. The $\mathrm{N}$-terminal region of RtxA has a motif homologous to several aminotransferases (Ruan and Peters 1992,, Ruan et al. 1993) as the $346 \mathrm{~N}$-terminal amino acids of RtxA exhibit $24 \%$ identity and $40 \%$ similarity to the aminotransferase of Methanobacterium thermoautotrophicum (Smith et al., 1997,). Mutants with a disruption of the N-terminal part of the protein were defective in serinol accumulation (Yasuta et al 2001,). The N-terminal domain of RtxA catalyzes the reaction from DHAP to serinol phosphate

\section{SpringerOpen ${ }^{\odot}$}



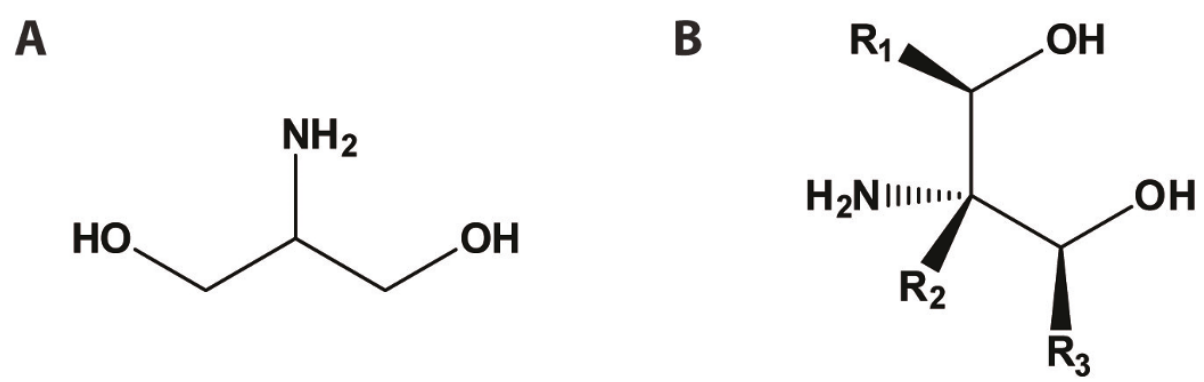

Figure 1 Structural formula of serinol (2-amino-1,3-propanediol) (A) and serinol as term for the group of C-substituted commercial analogs (B).

and further dephosphorylation to serinol (Yasuta et al. 2001 ,). Glutamic acid, followed by alanine and aspartic acid are the preferred amino donors for this transamination reaction (Andreeßen and Steinbüchel, 2011). Insertions in the $\mathrm{C}$-terminal part of the protein lead to a decrease of dihydrorhizobitoxine in B. elkanii USD94. The 443 C-terminal residues exhibit $41 \%$ identity and $56 \%$ similarity to the $\mathrm{O}$-acetylhomoserine sulfhydrolase of Leptospira meyer (Bourhy et al., 1997,). Therefore, Yasuta et al. (2001) concluded, that RtxA, exhibiting a molecular mass of $90 \mathrm{kDa}$, is a bifunctional enzyme comprising a dihydroxyacetone phosphate aminotransferase activity and a dihydrorhizobitoxine synthase activity at the same time. Dihydrorhizobitoxine is further converted to rhizobitoxine by the rhizobitoxine desaturase RtxC (Okazi et al. 2004). Introduction of the $r t x A C$ DEFG operon into Agrobacterium tumefaciens C58 resulted in serinol formation but no rhizobitoxine was synthesized (Sugawara et al. 2007).

\section{Natural occurrence of serinol-derivatives}

Besides the already described compound serinol (2-amino-1,3-propanediol), several chiral derivatives exist. Of particular importance are the acylated serinols (sphingosines). Sphingosine (Figure 2F) and its $\mathrm{N}$-acylated derivative, ceramide (Figure 2G), are central second messengers in eukaryotes. They are involved in regulation of cell growth, endocytosis, stress response, and apoptosis (Furuya et al. 1998,, Bieberich et al. 2000, Hannun and Luberto, 2000, Uchida et al., 2003). Several serinol derivatives were obtained from marine sponges (Molinsky 2004). From Stelletta inconspicua, for example, the $N$-acylated serinol inconspicamide ( $N$-palmitoyl2-amino-1,3-propanediol, Figure $2 \mathrm{H}$ ) has been extracted (Ueka et al. 2008). Spingosine and ceramide synthesis are best described in yeasts, e. g. Saccharomyces cerevisiae. Based on serine and palmitoyl-coenzyme A (CoA) 3-ketodihydrospingosine is condensated by a serine palmitoyltransferase and further reduced to dihydrosphingosine by a 3-ketosphinganine reductase. Ceramide is synthesized by the addition of a second palmitoyl moiety from palmitoyl-CoA, catalyzed by a ceramide synthase. Further modifications can occur by e. g. hydroxylases (Dickson and Lester, 2002). Among yeasts Pichia ciferri (formerly Hansenula ciferri) is of major industrial interest. They secrete tetra-acetyl-phytosphingosine (TAPS, Figure 2E) as the crystalline form to the medium, whereof it is easily purified (Wickerham and Stodola 1960,, Casey et al. 1995,, 1997, 13de Boer and van der Wildt 2001).

\section{Applications for serinol}

In general, aminoalcohols exhibit a multitude of applications in medicine and chemical industry. Long chain $\alpha, \omega$-aminoalcohols serve as fungizides (Nicholas et al., 2002,). Moreover, amino acid derived amino alcohols constitute important intermediates for enantiomerically pure substances (Cossy et al., 2009). Based on $N$ acetyl-1,3-amino alcohols, sphingosines for dermatological or generally pharmaceutical purposes can be synthesized (Singh et al., 2004,). Since the 1940s, serinol and its commercial C-substituted analogs were a popular motif in organic compounds (10,Darabantu 2010a and b). Synthetic $N$-acylated serinols $(N$-palmitoyl-2-amino-1,3-propanediol) are discussed to function as anti-cancer drugs as they increase ceramide-induced (Figure 2G) apoptosis (Bieberich et al. 2000, Ueoka et al. 2008). Furthermore, the synthetic sphingosine (Figure $2 \mathrm{~F}$ ) and, since 2010 the first oral drug in multiple sclerosis treatment, fingolimod (2-amino-2-[2-(4-octylphenyl) ethyl]propane-1,3-diol, Figure 2D) distributed as Gilenya ${ }^{\circledR}$ (Novartis) are synthesized from serinol (Buranachokpaisan et al., 2006). Moreover, chiral $(1 R, 2 R)$ phenylserinol (Figure 2B) is a common intermediate in industrial chloramphenicol (Figure $2 \mathrm{C}$ ) production (Darabantu et al., 1995,), and aromatic L-serinol-derivatives are important intermediates for epinephrine and norepinephrine synthesis (Nakazawa et al., 1975).

Serinol is also used as an intermediate for nonionic X-ray contrast agents like iopamidol $(1-N, 3-N-$ 


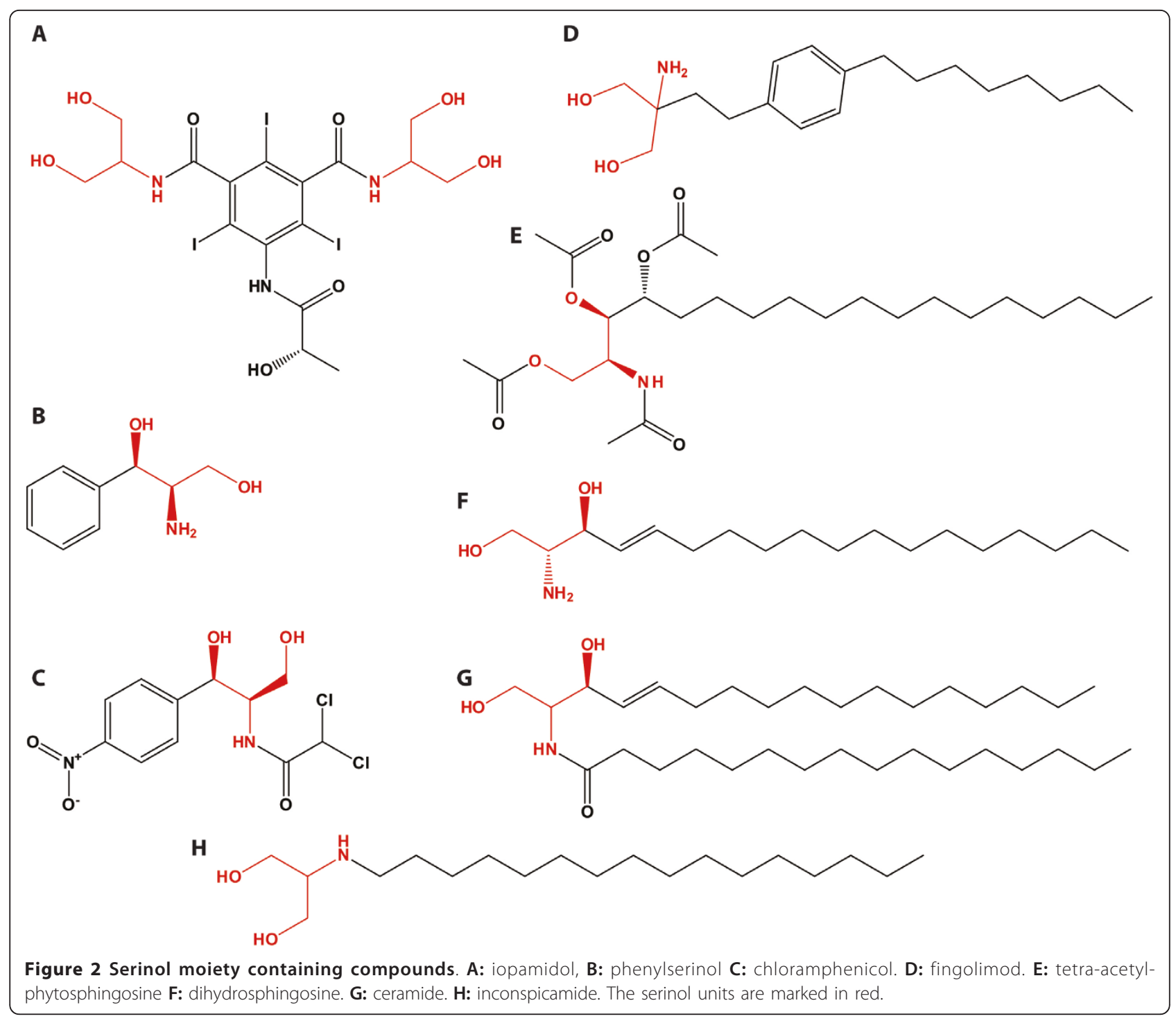

bis(1,3-dihydroxypropan-2-yl)-5-[(2S)-2-hydroxypropanamido]-2,4,6-triiodobenzene-1,3-di-carboxamide, Figure 2A), which is for example distributed as iopamiro $^{\circledR}$, isovue ${ }^{\circledR}$ (both Bracco Diagnostics Inc.) or scan$\operatorname{lux}^{\circledR}$ (Sanochemia). Iopamidol is employed as a contrast agent for angiography throughout the cardiovascular system (Villa and Paiocchi, 2003).

Furthermore, serinol constitutes a precursor for drugs dealing with pain treatment. Therefore, a straight or branched alkyl chain consisting of 12 to 22 carbon atoms is linked to the $\mathrm{C} 2$ atom of serinol (Michaelis et al. 2009).

\section{Chemical synthesis of serinol}

Until now serinol is normally produced by chemical synthesis (Figure 3). Most of the amino alcohols or their precursors are of petro-chemical origin or need hazardous reagents during synthesis (Piloty and Ruff, 1897,, Pfeiffer 1980,, Thewalt et al. 1984,, Felder et al. 1985,, Felder et al. 1987,, Fedoronko et al. 1989,, Quirk et al.1989,, Nardi et al. 1999,, Kodali 2008). Common fossil fuel derived precursors are 2-nitro-1,3-propanediol (Pfeiffer 1980,, Thewalt et al. 1984,, 16, Felder et al. 1985), nitromethane (Schmidt and Wilkendorf 1919,), dihydroxyacetone (DHA) (Felder et al. 1981), dihydroxyacetone oxime (Piloty and Ruff, 1897,, Fedoronko et al. 1989,, Nardi et al. 1999,) or 5-amino-1,3-dioxane (Quirk et al.1989).

The first synthesis of serinol was reported by Piloty and Ruff (1897). They reduced dihydroxyacetone oxime with sodium amalgam in presence of aluminum sulphate. For purification serinol was converted into the corresponding hydrochloride with yields up to $15 \%$ (wt/wt) relative to the oxime starting material. 


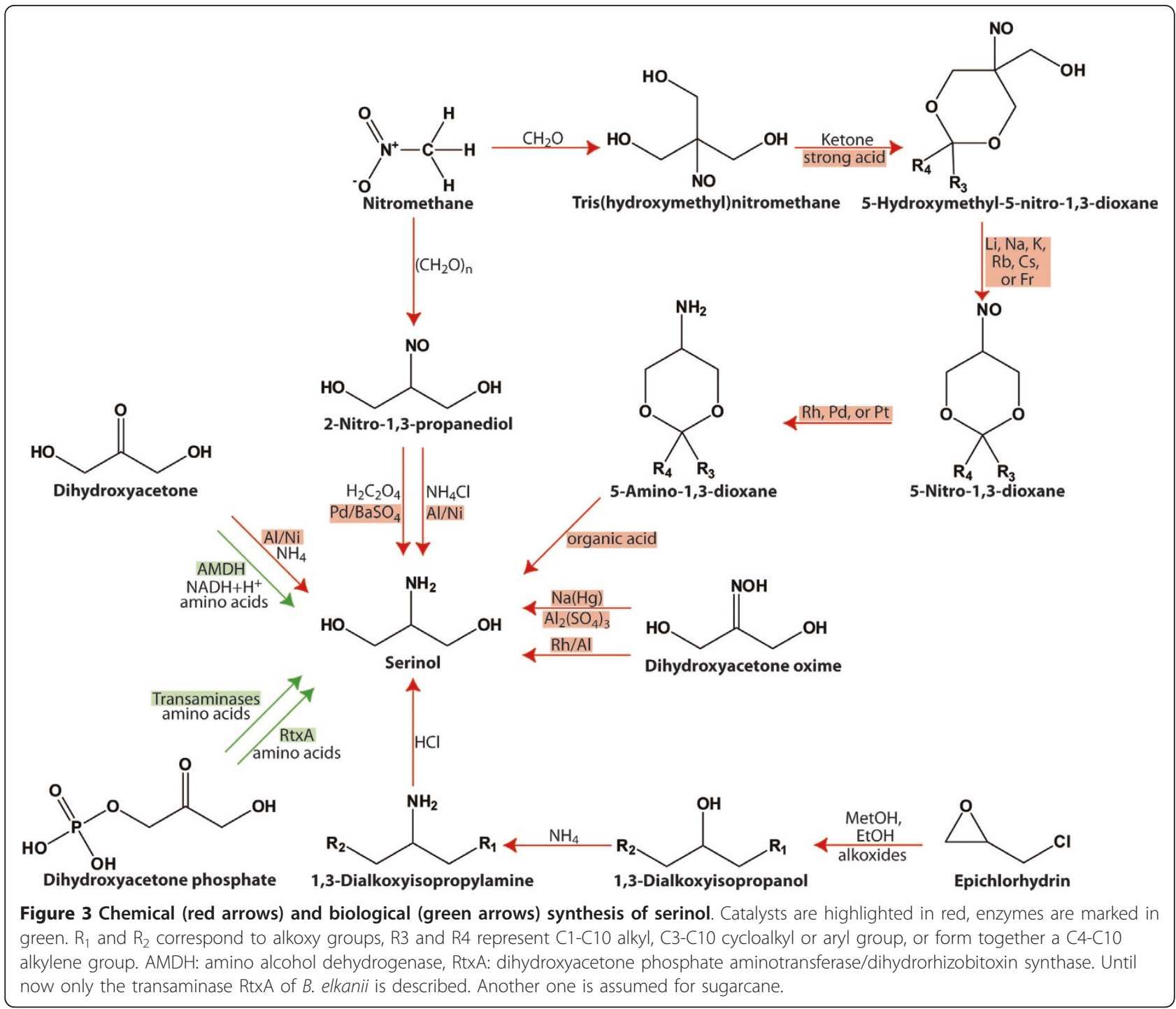

Schmidt and Wilkendorf (1919) synthesized several derivatives of 1,3-propanediol. First, $p$-formaldehyde and nitromethane condensate in presence of aqueous sodium hydroxide, then the accrued sodium salt of 2 nitro-1,3-propanediol, oxalic acid, and palladinated bariumsulfate react to serinol oxalate with yields up to $93 \%$ $(\mathrm{wt} / \mathrm{wt})$ of the theoretical value. The sodium salt of 2nitro-1,3-propanediol was also used as raw material for serinol production by Pfeiffer (1980). $\mathrm{Na}^{+}$-nitropropanediol dihydrate, ammonium chloride, and raney nickel as a catalyst were solved in methanol and incubated at room temperature and 70 bar pressure. After several distillation and purification steps $75.5 \%(\mathrm{wt} / \mathrm{wt}$ ) serinol with a purity of $99.6 \%$ were obtained. Application of palladium on carbon catalyst $(5 \% \mathrm{Pd} / \mathrm{C}, 50 \%$ water) instead of raney nickel gave 74.6 to $94.5 \%$ (wt/wt) serinol recovery with about $98.7 \%$ purity (Thewalt et al. 1984,). However, nitromethane as well as 2-nitro-1,3-propanediol are highly explosive. Consequently, Felder et al. (1985), used epichlorohydrin in presence of alkali with methanol or ethanol to form 1,3-dialkoxyisopropanol, which was further converted to 1,3-dialkoxy-isopropyl halide. Addition of ammonia or a primary or secondary amine formed a 1,3-dialkoxy-isopropylamine. In the last step the ether groups were separated by hydrochloric acid, yielding 80 to $91 \%$ (wt/wt) serinol with a purity of 99.8\%. Furthermore, they used DHA, ammonia, and raney-nickel as a catalyst, dissolved in methanol (100 bar, $70{ }^{\circ} \mathrm{C}$ ) for hydration (Felder et al. 1987). For purification, raw serinol was converted into the corresponding oxalate (yield: $87.2 \% \mathrm{wt} / \mathrm{wt}$ ).

Quirk et al (1989) used tris(hydroxymethyl)nitromethane derived from the reaction of nitromethane and 3 moles of formaldehyde instead of DHA or 2-nitro-1,3propanediol. Tris(hydroxymethyl)nitromethane and a ketone formed catalyzed by a strong acid $(\mathrm{HCl}$ or 
$\mathrm{H}_{2} \mathrm{SO}_{4}$ ) 5-hydroxymethyl-5-nitro-1,3-dioxane derivative. This derivative was converted into the corresponding 5-nitro-1,3-dioxane when treated with alkali. The nitro group was hydrogenated to an amino group employing rhodium, platinum or palladium catalysts. Serinol was isolated from the accrued 5-amino-1,3-dioxane in presence of a strong organic acid (Yield: 70 to $93 \% \mathrm{wt} / \mathrm{wt}$ ). Nardi et al. (1999) used dihydroxyacetone oxime with rhodium on aluminium as catalyst, incubated it for $16 \mathrm{~h}$ at $70{ }^{\circ} \mathrm{C}$ and 70 bar and obtained $90 \%$ (wt/wt) of crude serinol.

However, all these manufacturing processes exhibited partial disadvantages like unsatisfactory yields, formation of dangerous by-products or poorly accessible or fossil fuel derived raw materials (Thewalt et al. 1980,, Felder et al. 1987,). The expense of some reactants and the required equipment led to processes unsatisfactory for industrial applications (Quirk et al. 1989,). In addition, 1-amino-2,3-propandiol, which can be hardly separated from serinol, is generated during some chemical syntheses (Felder et al. 1987).

\section{Biotechnological synthesis of serinol}

Research on biosynthesis processes depending on a biological approach was only marginal (Figure 3). Nakazawa et al. (1975) applied different aldehydes to growing cultures of Brevibacterium helvolum, Candida humicola and Coryneacterium glycinophilum. The highest amounts of serinol derivatives were achieved with $C$. humicola and the substrates $p$-nitrobenzaldehyde or 3,4-dinitrobenzaldehyde $(8 \mathrm{~g} / \mathrm{l})$. The formation of serinol derivatives by $B$. helvolum or $C$. glycinophilum was slightly lower $(B$. helvolum and $p$-dimethylaminobenzaldehyde: $1.4 \mathrm{~g} / \mathrm{l}, C$. glycinophilum and $p$-nitrobenzaldehyde: $2.5 \mathrm{~g} / \mathrm{l})$.

Biotechnological production of the serinol derivatives sphingosine, dihydrosphingosine or phytosphingosine has already been established with several mutants of Pichia ciferri. These strains produce up to $0.8 \mathrm{~g} / \mathrm{l}$ TAPS when grown under batch culture conditions (Casey et al. 1995,, 1997,, de Boer and van der Wildt, 2001).

Serinol can be biochemically synthesized by amino alcohol dehydrogenases (AMDH). Itoh et al. (2000) isolated a strictly $\mathrm{NAD}^{+} / \mathrm{NADH}$-dependent $\mathrm{AMDH}$ from Streptomyces virginiae IFO 12827. The AMDH catalyzed the reversible dehydrogenation of serinol in presence of $\mathrm{NAD}^{+}$with a $K_{\mathrm{m}}$ value of $4.0 \mathrm{mM}$ to provide DHA, ammonium and NADH. The $K_{\mathrm{m}}$ for the back-reaction, the reductive amination of DHA, decreased to $2.2 \mathrm{mM}$ for DHA.

Our laboratory showed an artificial pathway for serinol production in recombinant Escherichia coli. For this, the bifunctional dihydroxyacetone phosphate aminotransferase/dihydrorhizobitoxin synthase RtxA or only its N-terminal domain (RtxA513), comprising the first reaction as described above, was heterologously expressed in E. coli. Up to $3.3 \mathrm{~g} / \mathrm{l}$ serinol were accumulated in the supernatant by the recombinant strains, possessing whether RtxA or RtxA513, growing in presence of glycerol as sole carbon source. As no higher yields were achieved, intracellular serinol content was considered to be toxic for the cells. To lower the probable toxic effect, conversion into the corresponding acylester was intended. But an in vitro derivatization employing wax ester synthase/acyl-CoA: diacylglycerol acyltransferase (WS/DGAT) from $A$. baylyi ADP1 was not possible (Andreeßen and Steinbüchel, 2011).

\section{Conclusions}

As described in this review, several applications for serinol or its derivatives are possible. Until now, large scale production of serinol is carried out via chemically processes (Piloty and Ruff, 1897,, Pfeiffer 1980,, Thewalt et al. 1984,, Felder et al. 1985,, Felder et al. 1987,, Fedoronko et al. 1989,, Quirk et al.1989,, Nardi et al. 1999, Kodali 2008). But most of these processes are based on fossil fuel derived precursors. In times of declining oil reserves, new methods for serinol synthesis or its derivatives are needed. The knowledge about microbial alternatives, summarized by this review, offers a good starting point for further research. The fermentative production of sphingosines by Pichia ciferri (Casey et al. 1995,, 1997,, 13,de Boer and van der Wildt, 2001) and serinol production from glycerol (Andreeßen and Steinbüchel, 2011) are promising examples for processes based on renewable resources.

\section{Acknowledgements}

Financial support from the BMVEL/FNR (FKZ 22015806, 06NR158) is gratefully acknowledged. We also acknowledge support by Deutsche

Forschungsgemeinschaft and Open Access Publication Fund of University of Muenster.

\section{Competing interests}

The authors declare that they have no competing interests.

Received: 16 April 2011 Accepted: 13 June 2011

Published: 13 June 2011

\section{References}

Andreeßen B, Steinbüchel A (2011) Biotechnological conversion of glycerol to 2-amino-1,3-propanediol (serinol) in recombinant Escherichia coli. DOI: 10.1007/s00253-011-3364-6

Babczinski P, Matern U, Strobel GA (1978) Serinol phosphate as an intermediate in serinol formation in sugarcane. Plant Physiol 61:46-49

Bieberich E, Kawaguchi T, Yu RK (2000) N-acylated serinol is a novel ceramide mimic inducing apoptosis in neuroblastoma cells. J Biol Chem 275:177-181

Bourhy P, Martel A, Margarita D, Saint Gl, Belfaiza J (1997) Homoserine O-acetyltransferase, involved in the Leptospira meyeri methionine biosynthetic pathway, is not retroinhibited. J Bacteriol 179:4396-4398

Buranachokpaisan T, Dannenfelser RM, Li P (2006) Compound formulations of 2amino-1,3-propanediol compounds. WO 2006010630 (A1) 
Cameron DC, Altaras NE, Hoffman ML, Shaw AJ (1998) Metabolic engineering of propanediol pathways. Biotechnol Prog 14:116-125

Casey J, Maume KA, Peters ALJ, Veloo RM (1995) Preparation of phytosphingosine derivative. EP688871-A, EP688871-A1, EP688871-A2, JP8168392-A, US5618706-A

Casey J, Maume KA, Peters ALJ, Veloo RM (1997) Preparation of phytosphingosine derivative. US5618706-A

Cossy J, Pardo DG, Dumas C, Mirguet O, Dechamps I, Metro TX, Burger B, Roudeau R, Appenzeller J, Cochi A (2009) Rearrangement of $\beta$-amino alcohols and application to the synthesis of biologically active compounds. Chirality 21:850-856

Darabantu M (2010a) (Masked) serinol: molecules, biomolecules, building-block, supramolecules. Part (I): syntheses based on serinols' reactivity with carbonyl electrophiles. Curr Org Synth 7:120-152

Darabantu M (2010b) (Masked) serinol: molecules, biomolecules, building-block, supramolecules. Part (II): serinolic approaches in current organic synthesis. Curr Org Synth 7:235-275

Darabantu M, Mager S, Plé G, Puscas C (1995) Heterocyclic saturated compounds as derivatives or precursors of chloromycetine and some related structures. Heterocycles 41:2327-2356

de Boer L, van der Wildt IFC (2001) Microbial strains producing sphingolipid bases. US patent 6204006

Dickson RC, Lester RL (2002) Sphingolipid functions in Saccharomyces cerevisiae. Biochim Biophys Acta 1583:13-25

Fedoronko M, Petrusova M, Alfoldi J (1989) Electroreduction of triose oximes. Chem Pap - Chem Zvesti 43:335-341

Felder E, Bianchi S, Bollinger H (1985) Process for the preparation of serinol and of serinol derivatives, and products obtained therefrom. US patent 4503252 (A)

Felder E, Römer M, Bardonner H, Härtner H, Fruhstorfer W (1987) Verfahren zur Herstellung von Hydroxyaminen. European patent 0238961 (A2)

Furuya S, Mitoma J, Makino A, Hirabayashi Y (1998) Ceramide and its interconvertible metabolite sphingosine function as indispensable lipid factors involved in survival and dendritic differentiation of cerebellar Purkinje cells. J Neurochem 71:366-377

Hannun YA, Luberto C (2000) Ceramide in the eukaryotic stress response. Trends Cell Biol 10:73-80

Itoh N, Yachi C, Kudome T (2000) Determining a novel NAD(+)-dependent amine dehydrogenase with a broad substrate range from Streptomyces virginiae IFO 12827: purification and characterization. J Mol Catal B: Enzym 10:281-290

Michaelis M, Geisslinger G, Scholich K (2009) 2-Amino-1,3-propanediol compounds for the treatment of acute pain. US patent 2004248988 (A1)

Mitchell RE, Frey EJ, Benn MK (1986) Rhizobitoxine and L-threo-hydroxythreonine production by the plant pathogen Pseudomonas andropogonis. Phytochemistry 25:2711-2715

Molinski RF (2004) Antifungal compounds from marine organisms. Curr Med Chem - Anti-Infective Agents 3:197-220

Nardi A, Villa M (1999) Process for the preparation of 2-amino-1,3-propanediol. US patent 5922917 (A)

Nakazawa H, Enei H, Kubota K, Okumura S (1975) Biological method of producing serine and serinol derivatives. US patent 3871958 (A)

Nicholas GM, Li RH, MacMillan JB, Molinski TF (2002) Antifungal activity of bifunctional sphingolipids. Intramolecular synergism within long-chain alpha, omega-bis-aminoalcohols. Bioorg Med Chem Lett 12:2159-2162

Noble MEM, Zeelen JP, Wierenga RK, Mainfroid V, Goraj K, Gohimont AC, Martial JA (1993) Structure of triosephosphate isomerase from Escherichia coli determined at $2.6 \AA$ resolution. Acta Crystallogr Sect D: Biol 49:403-417

Okazaki S, Sugawara M, Minamisawa K (2004) Bradyrhizobium elkanii rtxC gene is required for expression of symbiotic phenotypes in the final step of rhizobitoxin biosynthesis. Appl Environ Biotechnol 70:535-541

Owen LD, Thompson JF, Pitcher RG, Williams T (1972) Structure of rhizobitoxine, an antimetabolic enol-ether amino-acid from Rhixobium japonicum. J Chem Sci Chem Commun 1972:714

Pfeiffer H (1980) Process for the preparation of serinol (1,3-dihydroxy-2aminopropane). US patent 4221740 (A)

Piloty O, Ruff O (1897) Ueber einige Aminoalkohole der Fettreihe. Ber Dtsch Chem Ges 30:2057-2068

Quirk JM, Harsy SG, Hakansson CL (1989) Novel process for the preparation of serinol. European patent 0348223 (A2)

Ruan X, Peters NK (1992) Isolation and characterization of rhizobitoxine mutants of Bradyrhizobium japonicum. J Bacteriol 174:3467-3473
Ruan X, Zhang C, Peters NK (1993) Bradyrhizobium japonicum rhizobitoxine genes and putative enzyme functions: expression requires a translational frameshift. Proc Natl Acad Sci USA 90:2641-2645

Singh OV, Kampf DJ, Han HS (2004) Oxazine formation by MsCl/Et3N as a convenient tool for the stereochemical interconversion of the hydroxyl group in $\mathrm{N}$-acetyl 1,3-aminoalcohols. Asymmetric synthesis of $\mathrm{N}$-acetyl L-xylo- and L-arabino-phytosphingosines Tetrahedron Lett 45:7239-7242

Schmidt E, Wilkendorf R (1919) Über einige Derivate des Trimethylenglykols. Ber Dtsch Chem Ges 52:389-399

Smith DR, Doucette-Stamm LA, Deloughery C, Lee HM, Dubois J, Aldredge T, Bashirzadeh R, Blakely D, Cook R, Gilbert K, Harrison D, Hoang L, Keagle P, Lumm W, Pothier B, Qiu D, Spadafora R, Vicare R, Wang Y, Wierzbowski J, Gibson R, Jiwani N, Caruso A, Bush D, Safer H, Patwell D, Prabhakar S, McDougall S, Shimer G, Goyal A, Pietrovski S, Church GM, Daniels CJ, Mao Jl, Rice P, Nolling J, Reeve JN (1997) Complete genome sequence of Methanobacterium thermoautotrophicum $\Delta \mathrm{H}$ : functional analysis and comparative genomics. J Bacteriol 179:7135-7155

Sugawara M, Haramaki R, Nonaka S, Ezura H, Okazaki S, Eda S, Mitsui H, Minamisawa K (2007) Rhizobitoxine production in Agrobacterium tumefaciens C58 by Bradyrhizobium elkanii rtxACDEFG genes. FEMS Microbiol Lett 269:2-35

Thewalt K, Bison G, Egger H (1984) Process for the preparation of 2aminopropanediol-1,3 (serinol). US patent 4448999 (A)

Uchida Y, Nardo AD, Collins V, Elias PM, Holleran WM (2003) De novo ceramide synthesis participates in the ultraviolet B irradiation-induced apoptosis in undifferentiated cultured human keratinocytes. J Invest Dermatol 120:662-669

Villa M, Paiocchi M (2003) Process for the purifying of iopamidol. US patent 6506938 (B1)

Wickerham LJ, Stodola FH (1960) Formation of extracellular sphingolipides by microorganisms I. Tetraacetylphytosphingosine from Hansenula ciferri. J Bacteriol 80:484-491

Yasuta T, Okazaki S, Mitsui H, Yuhashi Kl, Ezura H, Minamisawa K (2001) DNA Sequence and mutational analysis of rhizobitoxine biosynthesis genes in Bradyrhizobium elkanii. Appl Environ Microbiol 67:4999-5009

Yuhaschi Kl, Ichikawa N, Ezura H, Akao S, Miniakawa Y, Nukui N, Yasuta T, Minamisawa K (2000) Rhizobitoxine production by Bradyrhizobium elkanii enhances nodulation and competitveness on Macroptilium atropurpureum. Appl Environ Microbiol 66:2658-2663

doi:10.1186/2191-0855-1-12

Cite this article as: Andreeßen and Steinbüchel: Serinol: small molecule big impact. AMB Express 2011 1:12.

\section{Submit your manuscript to a SpringerOpen ${ }^{\circ}$ journal and benefit from:}

- Convenient online submission

- Rigorous peer review

- Immediate publication on acceptance

- Open access: articles freely available online

- High visibility within the field

- Retaining the copyright to your article

Submit your next manuscript at $\gg$ springeropen.com 